\title{
Pistas dos processos de decodificação que levam à compreensão da leitura
}

\author{
Cues of decoding processes that lead to the reading comprehension
}

Pistas de procesos de decodificación que llevan a la comprensión de la lectura

\author{
Alessandra Pereira Gomes Machado ${ }^{1}$ \\ Raquel Meister Ko. Freitag (1) 1 \\ ${ }^{1}$ Universidade Federal de Sergipe, São Cristóvão, SE, Brasil.
}

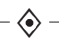

\begin{abstract}
RESUMO
A fluência em leitura em voz alta pode repercutir nos resultados de avaliações em larga escala que avaliam a proficiência na compreensão em leitura. Experiências internacionais sugerem que o diagnóstico dos processos de decodificação com automaticidade possibilita o desenvolvimento dos processos de compreensão, solução que pode ser adotada no sistema educacional brasileiro. O objetivo deste texto é apresentar uma proposta de diagnóstico de perfil de leitor quanto à compreensão a partir do controle da fluência em leitura em voz alta, considerando as pistas de processos de automaticidade na decodificação que levam à compreensão da leitura. Seguimos o método Curriculum-Based Measurement (DENO, 2003) para a avaliação da fluência em leitura em voz alta e testamos o instrumento com estudantes de $6^{0}$ e 9 음 ano de escolas públicas de Sergipe.
\end{abstract}

Palavras-chave: Leitura em voz alta. Compreensão leitora. Diagnóstico.

\begin{abstract}
Reading aloud fluency may have repercussions on the results of large-scale assessments that measure proficiency in reading comprehension. International experiences suggest that the diagnosis of decoding with automaticity processes enables the development of comprehension processes, and it is a solution that can be adopted in the Brazilian educational system. The purpose of this text is to present a proposal of a reader profile diagnosis with the control of fluency in reading aloud, considering the clues of automation processes in the decoding during the reading comprehension. This propose followed the Curriculum-Based Measurement method (DENO, 2003) for the evaluation of fluency in reading aloud and tested the instrument with $6^{\text {th }}$ and $9^{\text {th }}$ grade students from public schools from Sergipe.
\end{abstract}

Keywords: Reading aloud. Reading comprehension. Diagnosis.

\section{RESUMEN}

La fluidez en lectura en voz alta puede repercutir en los resultados de evaluaciones a gran escala que evalúan la habilidad en la comprensión en lectura. Las experiencias internacionales sugieren que el diagnóstico de los procesos de decodificación con automaticidad posibilita el desarrollo de los procesos de comprensión, solución que se puede adoptar en el sistema educativo brasileño. El objetivo de este texto es presentar una propuesta de diagnóstico de perfil de lector en cuanto a la comprensión a partir del control de la fluencia en lectura en voz alta, considerando las pistas de procesos de automaticidad en la decodificación que llevan a la comprensión de la lectura. Seguimos el método Curriculum-Based Measurement (DENO, 2003) para la evaluación de la fluencia en lectura en voz alta y probamos el instrumento con estudiantes de $6^{0}$ y $9^{\circ}$ años de escuelas públicas de Sergipe.

Palabras clave: Lectura en voz alta. Comprensión lectora. Diagnóstico. 


\section{Introdução}

Em $A$ arte de Ler, Morais (1996) apresenta uma tipologia de leitores: aprendiz, hábil e fracassado. Os leitores aprendizes (ou iniciantes) estão na condição de "aprender a ler". A primeira condição da aprendizagem inicial da leitura atende à tomada de consciência do princípio alfabético da correspondência entre fonemas e grafemas que exige atividades de análise e de comparação de sílabas faladas e escritas que devem ser asseguradas na fase do "aprender a ler". Essa condição é necessária para adquirir progressivamente outras duas condições que atendem ao conhecimento do sistema ortográfico da língua e da construção do léxico mental ortográfico, domínios necessários para o desenvolvimento dos processos de decodificação com automaticidade para formar o leitor hábil. Isso quer dizer que uma condição depende da anterior, como nas fases da aprendizagem inicial da leitura (FRITH, 1985; EHRI, 2013; MORAIS; LEITE; KOLINSKY, 2013).

Já o leitor hábil atingiu a maturidade plena de quem passou da aprendizagem inicial da leitura para leitor fluente. No Brasil, no fim do $3^{\circ}$ ano do Ensino Fundamental, o estudante deve ser suficientemente eficiente para ler com fluência (BRASIL, 1998). A automaticidade na decodificação é condição para se tornar um leitor hábil, eficiente, experiente e proficiente, ou seja, um bom leitor. No entanto, é necessário desenvolver as condições da aprendizagem inicial da leitura, conduzindo o leitor iniciante a descobrir o princípio alfabético, ensinar-lhe o código e a maneira de se servir dele.

E o leitor fracassado é aquele que não desenvolveu as condições necessárias da aprendizagem inicial da leitura na etapa adequada a esse processo; e o acesso tardio a essas condições não permite recuperar o tempo dessa aprendizagem, promovendo o leitor ao fracasso na leitura. É o leitor que não conseguiu desenvolver os processos do "aprender a ler", das habilidades específicas para o desenvolvimento cognitivo do processamento da informação na leitura, processos específicos desenvolvidos pelo leitor aprendiz que atingem a maturidade no leitor hábil. O nível da habilidade desenvolvida na aprendizagem inicial da leitura não distingue os bons leitores, no entanto, se não desenvolvido durante a aprendizagem da leitura, distingue, de maneira clara, os "maus" dos "bons" leitores (MORAIS; LEITE; KOLINSKY, 2013).

Os resultados das avaliações oficiais brasileiras em larga escala, como a Avaliação Nacional da Alfabetização (ANA) e da Prova Brasil (Avaliação Nacional do Rendimento Escolar -Anresc), avaliações censitárias que abrangem estudantes de escola pública dos anos iniciais e finais do ensino fundamental realizadas pelo Instituto de Pesquisas Educacionais Anísio Teixeira (INEP), assim como os resultados do Programme for International Student Assessment (PISA), da Organização para a Cooperação e Desenvolvimento Econômico (OCDE), avaliação internacional, apontam que o desenvolvimento em compreensão leitora não atende ao esperado por estudantes das séries avaliadas.

Um problema das avaliações oficiais é que seus resultados são divulgados com uma distância temporal que não permite que ações sejam realizadas para corrigir as assimetrias. Considerando que a leitura envolve processos de decodificação e de compreensão, os processos de decodificação com automaticidade são necessários para a compreensão do texto lido. Se os processos de decodificação não estão automatizados, a compreensão é comprometida, o que pode interferir nos resultados das avaliações em larga escala de compreensão de leitura. Assumindo que a automaticidade na decodificação é preditora para a compreensão da leitura, o objetivo deste texto é apresentar uma proposta de diagnóstico de perfil de leitor quanto à compreensão a partir do controle da fluência em leitura em voz alta. Os tipos de leitores podem ser balizados a partir dos seus níveis de fluência em leitura em voz alta, especificamente pelas pistas identificadas nos processos de automaticidade na decodificação que levam à compreensão da leitura.

Na situação de sala de aula, como identificar os perfis de leitor? Propomos que é possível identificá-los a partir da leitura em voz alta, controlando pistas de fluência em leitura em voz alta que podem predizer a compreensão leitora. Para tanto, seguimos a proposta do método Curriculum-Based Measurement (DENO, 2003), que é usado na avaliação da fluência em leitura em voz alta (RASINSKI, 2004; HASBROUCK; TINDAL, 2006). A partir da leitura em voz alta de dois textos adequados ao nível de escolaridade do leitor, é realizada a mensuração para análise de 1 minuto de leitura em voz alta. O método Curriculum-Based Measurement foi utilizado por Vansiler (2015), Moutinho (2015) e Oliveira (2015) para estudo de fluência no português brasileiro. Cada um dos estudos considerou uma das dimensões do teste; nesta proposta, consideramos, conjuntamente, parâmetros das três dimensões.

\section{Fluência em leitura em voz alta e compreensão leitora}

Considerando que a leitura implica em habilidade específica de extração da informação e em habilidade de transformar a informação em processos que levam à compreensão, os processos de reconhecimento de letras, sílabas e palavras impressas que estão na superfície do texto são entendidos como decodificação da palavra escrita e é o modo específico de aquisição de informação 
(MORAIS, 1996; DEHAENE, 2012). Os processos de compreensão envolvem a utilização dessa informação para construir uma representação coerente com o texto escrito (SMITH, 2004; PERFETTI; LANDI; OAKHILL, 2013; PERFETTI; STAFURA, 2014). Nesse processo de construção do sentido, o leitor que monitora a leitura tem maior domínio cognitivo do processo de compreensão leitora (OAKHILL; HARTT; SAMOLS, 2005; EFKLIDES, 2008) e a capacidade de reconhecimento da palavra com automaticidade leva à compreensão do texto lido (LABERGE; SAMUELS, 1974).

A fluência em leitura em voz alta é uma habilidade complexa que implica em várias tarefas para o leitor traduzir automaticamente palavras escritas em representações convergentes aos sons, acessando automaticamente representações lexicais, processando conexões dentro e entre orações, relacionando o significado do texto com informações prévias e fazendo inferências para fornecer informações que faltam (FUCHS, D.; FUCHS, L.; HOSP, 2001).

Nessa perspectiva da fluência, para a análise da leitura em voz alta, três componentes são elementoschave: precisão na decodificação da palavra, velocidade de leitura e uso apropriado da prosódia (RASINSKI, 2004). A precisão na leitura em voz alta refere-se à habilidade de decodificar a palavra escrita corretamente (RASINSKI, 2004). Para a precisão de leitura, é necessário que o leitor tenha conhecimento do sistema alfabético e das relações de transparência do sistema ortográfico da língua, além de ter um amplo vocabulário (palavras frequentes).

A velocidade de leitura é a habilidade de ler palavras e textos com a velocidade apropriada (RASINSKI, 2004). A prática de ler pode tornar o desempenho mais automatizado e, consequentemente, mais rápido. Assim, a velocidade de leitura aumenta ao longo do desenvolvimento e da prática de leitura, mas o melhor estágio para ampliar essa habilidade é no início da escolarização (LOGAN, 1997; EHRI, 2013). A análise da velocidade como única dimensão da fluência em leitura em voz alta não identifica o leitor fluente (KOMENO et al., 2015), assim como ensinar o estudante a ler muito rápido não significa necessariamente que ele será mais fluente ou melhor "compreendedor" (RASINSKI, 2000). $\mathrm{Na}$ decodificação com automaticidade, o reconhecimento da palavra escrita se torna mais rápido e mais preciso e direciona recurso cognitivo para centrar-se nos processos de compreensão do texto (LABERGE; SAMUELS, 1974).

E a prosódia é a dimensão da fluência em leitura em voz alta que mais evidencia a compreensão do texto, uma vez que o uso apropriado dos elementos prosódicos reflete que o leitor está entendendo o que está lendo; esta é, no entanto, a dimensão ainda menos trabalhada no diagnóstico da fluência (FUCHS, D.; FUCHS, L.; HOSP, 2001; RASINSKI, 2004).

Considerando que automaticidade na decodificação pode ser preditora da compreensão de leitura, o controle de processos nas três dimensões da fluência em leitura em voz alta pode auxiliar a identificar o perfil do leitor.

\section{Pistas da compreensão leitora na fluência em leitura em voz alta}

\subsection{Fenômenos variáveis da fala}

A relação grafofonêmica no português não é unívoca; há variação. A variação que é característica de uma língua também passa para a leitura em voz alta. Considerar as pistas da passagem de fenômenos variáveis da fala para a leitura pode auxiliar a medir a fluência em leitura em voz alta. Seguindo a proposta de Bortoni-Ricardo (2004), os traços variáveis, no português brasileiro, podem ser graduais, que perpassam todos os contextos sociais e estilísticos, ou descontínuos, que são característicos de um dado contexto (como o contínuo rural-urbano, por exemplo). Sejam graduais ou descontínuos, a presença destes traços na leitura em voz alta sugere o acesso à rota lexical de leitura de palavras frequentes (AQUINO, 2011); diferentemente do uso da rota fonológica para as palavras com todas as correspondências grafofonêmicas (FREITAG; PINHEIRO; SILVA, 2017; MACHADO, 2018a; FREITAG; SÁ, 2019). Fenômenos não estigmatizados na fala da comunidade passam sistematicamente para a leitura, o que pode ser uma pista para a identificação de leitores hábeis, por acessarem diretamente a rota lexical. Esta é uma proposta de controle diferente da pressuposta por outras abordagens (RASINSKI, 2000, 2004; RASINSKI et al., 2005, 2011; HASBROUCK; TINDAL, 2006; TRISTÃO, 2009; CASTANHEIRA, 2011) que assumem a homogeneidade e a transparência com o sistema alfabético, taxando toda a realização em voz alta que foge do padrão da escrita ortográfica como erro e tomam como base na avaliação da precisão em leitura.

\subsection{Hipercorreção}

A hipercorreção está relacionada aos fenômenos variáveis da fala e é insegurança linguística que o falante, em uma situação em que uma variedade é considerada de estigma em relação a uma de prestígio, tenta aproximarse da variedade de prestígio, cometendo exageros ou impropriedades (LABOV, 1972). Esses "exageros" podem ser considerados como hipóteses de antecipação ou predições malsucedidas do ponto de vista de adequação à norma (BORTONI-RICARDO, 2004). 
(1) desejar que muitas mais pessoas possam também desfrutar-lo (NNS-9MEFF-08.16-V1-T2) ${ }^{1}$.

Em (1), de acordo com a norma padrão, o verbo "desfrutar" acompanhado do pronome proclítico perde a desinência de infinitivo, mas foi lido como desfrutar-lo, com a realização não prevista do infinitivo, ocasionando a hipercorreção.

\subsection{Erro de decodificação}

O erro de decodificação é explicado a partir do acesso à rota fonológica na leitura de palavras que não são frequentes para o leitor (COLTHEART et al., 2001; COLTHEART, 2013). No processo de decodificação com automaticidade, o leitor fluente acessa a palavra escrita pela rota lexical, que concentra todas as informações ortográfica, fonológica e semântica, tornando a leitura mais fácil. Esse processo ocorre com as palavras frequentes do repertório linguístico do leitor, como no excerto (2), em que o leitor dá pistas de conhecer todas as palavras e o acesso se dá pela rota lexical, uma vez que ocorre o apagamento do $\mathrm{R}$ em coda de infinitivo dos verbos (traço gradual) "ter", "comer" e "comprar" lidos como "tê", "comê" e "comprá".

(2) ((quando)) quando eu era menina queria tê uma fábrica de doces só para comê todos os doces que eu quisesse... naquela época eu era muito pobre e quase nunca sobrava dinheiro lá em casa para comprá doces (ALMF-6MEFF-08.16-V1-T1).

No entanto, se o leitor precisa direcionar a atenção para a palavra escrita, podemos identificar o acesso à rota fonológica, em que há uma maior preocupação com a relação grafofonêmica da palavra, tendo como efeito de superfície a leitura mais lenta e difícil. Esse processo pode ocorrer com as palavras que não fazem parte do repertório linguístico do leitor, portanto, não são frequentes ou são palavras irregulares, como em (3), em que o leitor acessa a rota fonológica para decodificar as palavras que não são frequentes, como a palavra "pracinha". No reconhecimento da palavra escrita, o estudante faz uma leitura grafofonêmica das sílabas "pra-ci-nha", mas ao ler a palavra, não a tem em seu léxico mental e pronuncia "pracilha".

\footnotetext{
1 O excerto é a transcrição ortográfica adaptada da leitura em voz alta da pesquisa de campo. Destacamos em itálico o fenômeno sob análise. Ao final, o código identifica, nas letras iniciais, o participante (ALMF; em seguida a série (sexto ano), o turno (matutino), e a escola (neste caso EEF se refere à escola de ensino fundamental federal; EFE, escola de ensino fundamental estadual). Os números se referem à ordem da gravação e do armazenamento; e, ao fina, $\mathrm{V}$ e T se referem à versão da leitura (1a ou 2a) e ao texto lido. Os detalhes da coleta são apresentados na seção 3 deste artigo.
}

(3) todos os dias a menina estava... lá... vendia doce... na porta de uma lanchonete... perto de uma... pra-ci-nha \{pracilha\} onde brincava... (brincam)... quase todos as crianças... da... redos-.../redon-... deza (BRVS-6MEFF08.16-V1-T1).

Neste tipo de leitura em voz alta, em que não há o reconhecimento da palavra escrita de modo a construir um significado coerente com a escrita, consideramos como um erro de decodificação. Essa dificuldade está relacionada ao processo de decodificação e aponta que no reconhecimento da palavra escrita não foram processadas as informações ortográfica, fonológica e semântica de forma conjunta, comprometendo o processo de construção semântica, e dá pistas de que a compreensão pode ser comprometida.

\subsection{Falta de conhecimento do sistema alfabético}

A falta de conhecimento do sistema alfabético leva o leitor a acessar a rota fonológica, demonstrando falta de automaticidade.

A ortografia de uma língua alfabética é definida pelas letras e sons e seus correspondentes grafofonêmicos. Línguas com sistema ortográfico transparente apresentam maior correspondência biunívoca entre os segmentos fonológicos e os símbolos gráficos. O sistema ortográfico de algumas línguas, no entanto, apresenta uma relação menos direta com a fonologia. Assim, as palavras escritas neste sistema não podem ser pronunciadas prontamente, relacionando grafemas a fonemas, mas requerem do leitor conhecimento morfêmico e semântico. E a falta de conhecimento da transparência do sistema ortográfico interfere na automaticidade da decodificação em leitura.

No português brasileiro, há grafemas representados de forma biunívoca com seu correspondente fonêmico, como em "bala", demonstrando uma relação transparente do sistema ortográfico. No entanto, em outros contextos não há a mesma transparência, como em um fonema representado por grafemas diferentes, como em "nasci" e "experiência", embora no português brasileiro, estes casos sejam poucos (SCLIAR-CABRAL, 2003).

A falta de conhecimento das regras de conversão pode causar dificuldades na leitura de palavras que não são frequentes para o leitor, como em (4), em que a palavra "termo" (vogal média alta) foi lida como "térmo" (vogal média baixa):

(4) é claro queu... uso... esse térmo... professorinha com muito afeto (MBAL-6TEFE-05.16-V1-T2).

As vogais tônicas orais são basicamente idênticas para todos os dialetos do português, no entanto, são 
passíveis de variação por alçamento (BISOL, 1996). Na leitura em voz alta, é possível identificar quando o leitor não está familiarizado com a transparência do sistema ortográfico da língua, o que pode afetar o acesso à rota lexical, e, por tabela, a compreensão.

\subsection{Ressilabação}

A ressilabação é um processo da oralidade que consiste no agrupamento de "constituintes em torno de picos de sonoridades, que projetam sílabas. Esses picos são em português necessariamente vogais" (BISOL, 1996, p. 161). A ressilabação segue os mesmos princípios da silabação. A diferença é que a silabação ocorre no componente lexical, responsável pela formação dos itens lexicais. Já a ressilabação ocorre no componente pós-lexical, isto é, no resultado da sintaxe (BISOL, 1996) e pode ser identificada na leitura em voz alta.

O leitor que realiza a ressilabação na leitura em voz alta demonstra conhecer a sintaxe da língua, por esse processo desempenhar uma importante função de juntar os termos que fazem parte de um mesmo bloco semântico-sintático.

(5) todozos dias (as) a menininha estava lá vendia doces na porta de uma lanchonete (ALMF-6MEFF-08.16V1-T1).

Em (5), no sintagma "todos os dias", a juntura de "todos os" ocorre por meio de processo de reestruturação silábica. Na ressilabação de "S" em coda com o clítico pós-lexical "os", o [s] passa a ocupar o ataque com características de $[\mathrm{z}]$, permitindo identificar a junção. Esse processo de ressilabação entre o quantificador e o determinante deve ser realizado na leitura em voz alta do leitor hábil por compor uma estrutura sintática indissociável. A ressilabação também possibilita distinguir a realização da concordância nominal de número entre os elementos e o núcleo de um sintagma nominal. O leitor que não realiza ressilabação neste contexto sinaliza que não está realizando parsing adequado para o processamento das informações sintáticas, o que pode sinalizar problemas na compreensão.

\subsection{Predições}

O leitor hábil lê por meio de um jogo psicolinguístico de adivinhação (GOODMAN, 1967), fazendo predições por meio de estratégias de seleção, antecipação, inferência e verificação de pistas apoiadas no conhecimento linguístico e prévio, com objetivo de construção do significado. Estas pistas serão refutadas ou aceitas, conforme o contexto da leitura. Os processos preditivos devem ser realizados com a maior precisão possível para a construção do significado do texto; no entanto, os leitores preocupados diretamente com a palavra, isto é, com a atenção voltada para a decodificação, terão problemas com a realização de predição e, consequentemente, com a compreensão (SMITH, 2004).

$\mathrm{Na}$ leitura em voz alta, não temos acesso às predições bem-sucedidas. Mas podemos identificar as tentativas de predição, ou predições não exitosas, que deixam pistas sintáticas e semânticas: predição de palavra da mesma classe gramatical e mesmo campo semântico, mesma classe gramatical e campo semântico diferente, classe gramatical diferente e mesmo campo semântico e classe gramatical e campo semântico diferentes, mesma classificação adotada por Abreu et al. (2017) no teste cloze para a compreensão.

Em (6), o leitor inferiu "falava" no lugar de "faltava", construindo uma informação que não atende ao sentido do texto, e se não houver reparo, pode acabar interferindo na compreensão.

(6) nos finais de semana ela chegava mais tarde mas nunca falava (DMSS-6MEFF-08.16-V1-T1).

A distinção entre as predições não exitosas permite acompanhar os caminhos que o leitor faz em sua leitura quanto à compreensão: uma predição no mesmo campo semântico e classe gramatical sinaliza para a compreensão; já uma predição em um campo semântico distinto e em uma classe gramatical distinta sinaliza para um leitor "adivinhador"; se não houver reparo (autocorreções, seção 3.7) ou as predições não exitosas forem frequentes, a compreensão é prejudicada.

\subsection{Autocorreções}

As autocorreções são o resultado de processos metacognitivos realizados pelo leitor para corrigir predições não exitosas, consideradas hipóteses não confirmadas na construção do significado do texto, e podem funcionar como pistas de compreensão na leitura em voz alta. As autocorreções mostram que o leitor está consciente de que a palavra pronunciada não atendeu ao significado do texto.

(7) eles às vezes (entram) seu... estranham seus gostos musicais... vocabulário (ASB-9MEFF-08.16-V1-T1).

Em (7), o leitor leu o verbo "entram" e, consciente da predição não exitosa, realiza a tarefa metacognitiva de corrigir e ler "estranham" para adequar à palavra escrita, com intuito de compreender o texto. As autocorreções 
sinalizam que o monitoramento está acontecendo, em prol da compreensão da leitura.

\subsection{Repetições}

As repetições fazem parte dos processos metacognitivos do monitoramento da compreensão da leitura. $\mathrm{O}$ monitoramento permite que o leitor verifique a compreensão; e as repetições consistem no processo de ler novamente a palavra ou parte desta como recurso para compreender a leitura como parte da formulação e reformulação de predições, que confirmam ou descartam as hipóteses para atender à compreensão da leitura.

(8) minha alfabetização... não... me foi nada enfa-... enfado-... enfadonha (ECSS-6MEFF-08.16-V1-T2).

Em (8), a repetição de partes da palavra "enfadonha" demonstra o processo metacognitivo de planejamento de busca na memória lexical dessa palavra, que parece ser não frequente para o leitor. A ocorrência desse processo é resultado do monitoramento da compreensão da leitura.

\subsection{Pausa silenciosa e preenchida}

A pausa é um elemento prosódico que apresenta um valor tanto textual, de processamento da informação, como sintático. Quando funciona como marca de processamento linguístico, relaciona-se à sintaxe e pode ocorrer em três lugares no enunciado: 1) fronteiras de constituintes maiores (entre orações e entre sujeito e predicado); 2) entre um determinante e o núcleo do sintagma; e 3) em correções de falsos começos e repetições (SCARPA; FERNANDES-SVARTSMAN, 2012). As pausas ocorridas em 1) são consideradas adequadas e fluentes. No entanto, se o leitor desobedece ao momento adequado de pausa, como em 2) e 3), configura-se como disfluente ou de hesitação. Scarpa (1995, p. 171) esclarece que "trechos fluentes são os já ajeitados, conhecidos, analisados ou, na maioria dos casos, congelados, vêm em bloco. Os disfluentes são aqueles em construção, instáveis, com tentativas infrutíferas de segmentação em blocos prosódicos."

$\mathrm{Na}$ fala, pausas apresentam correlação com o tipo de fronteira de constituintes (FREITAG; PINHEIRO; SILVA, 2017) e podem funcionar como pista de processo de planejamento na fala entre interlocutores. Na leitura em voz alta, em que a estrutura sintática já está organizada, a pausa também pode ser considerada uma pista do processo metacognitivo de monitoramento da leitura, atuando no processo de planejamento junto com as repetições e, no de avaliação da leitura, os reparos, para adequar ao texto escrito. Porém, são consideradas disfluentes se ocorrerem em contextos inapropriados, que sinalizam para a não compreensão.

A pausa silenciosa é definida como o período de silêncio durante a fala, ocorrido entre vocalizações com duração de 250 milissegundos (ms) (OLIVEIRA, 2002), como ponto de corte para cotação do silêncio. As pausas controladas são as que se configuram como desobediência à organização de blocos sintáticos prosódicos. Enquanto pista do componente de estrutura sintática na leitura em voz alta, para predizer a compreensão, interessa o local onde não pode haver uma pausa silenciosa, porque sua ocorrência sinaliza falta de conhecimento sintático e semântico no processamento de blocos de sentido que interferem para a compreensão do texto.

(9) é um amor que vem desde a infância que me tem... $(312 \mathrm{~ms})$ acompanhado a vida inteira (MWSS-9TEFE05.16-V1-T2).

Em (9), o leitor realizou uma pausa silenciosa de $312 \mathrm{~ms}$ ao ler a forma verbal composta "tem acompanhado", realizando uma pausa silenciosa maior que o esperado. Esse tempo de processamento sugere que o leitor não organizou a leitura em blocos de significado, realizando pausa silenciosa em local indevido, o que pode evidenciar dificuldade na construção do significado do texto.

(10) a primeira... $(0,340)$ presença... $(0,530)$ em meu... (310ms) aprendizado escolar (ISP-6MEFE-05.16V1-T2).

Em (10), o leitor realizou uma pausa silenciosa de $310 \mathrm{~ms}$ entre o determinante (meu) e o núcleo do sintagma nominal (aprendizado), demonstrando dificuldade no processamento sintático do sintagma "em meu aprendizado escolar".

Por outro lado, a pausa preenchida indica que o leitor "preenche o tempo com sons que não configuram itens lexicalizados" (ALMEIDA, 2009, p. 109), como “ah", "eh", “oh", "né”, “af". Esse tipo de pausa configura hesitação e demonstra correção da leitura ou mesmo como uma interação com o ouvinte da leitura em voz alta, solicitando confirmação de uma predição realizada.

(11) minha alfabetização não me foi nada... $(0,660)$ \{afadonha $\}. . .(0,390)$ en- oh /enfadonha (GWSP6MEFE-05.16-V1-T2).

Em (11), o leitor percebeu que havia cometido um erro de decodificação ao ler "enfadonha" e fez uma expressão exclamativa, utilizando o marcador de correção "oh", caracterizado como pausa preenchida entre determinante 
e núcleo de sintagma, considerada disfluente, no intuito de corrigir a leitura.

\subsection{Mudança de fronteira}

Como a ressilabação, a mudança de fronteira é um processo prosódico que pode ser identificado na leitura em voz alta. O tom atribuído ao final de fronteira se associa fonologicamente ao limite de uma frase, demarcado pelo ponto final do texto escrito e pelo limite de fronteira de constituinte prosódico (ALVES et al., 2009). No entanto, quando o leitor não realiza a pausa silenciosa, indicativa da fronteira de constituinte, ocorre uma mudança de fronteira no limite prosódico. Essa ausência de pausa silenciosa pode resultar em inferências não exitosas na compreensão da leitura.

(12) não brincava $(0,230) \mathrm{s}-\ldots(0,428)$ só vendia... $(0,341)$ doces mesmo... (440ms) porque ela... $(0,160)$ não era... $(0,252)$ mora-... $(0,329)$ moradora... (DFG-6MEFE05.16-V1-T1).

Em (12), de acordo com o texto escrito, o leitor deveria ter lido "só vendia doces. Mesmo porque ela não era moradora", realizando um tom de fronteira ascendente e identificando o limite dessa fronteira. No entanto, ele muda o limite da fronteira para depois do "mesmo", incorrendo em mudança sintática que leva à implicação semântica. Neste caso, a mudança de fronteira sinaliza para a não compreensão da leitura.

\section{Instrumento de avaliação das pistas de compreensão leitora}

As pistas controladas para avaliar a compreensão a partir da leitura em voz alta podem apontar para maior ou menor probabilidade de compreensão leitora, conforme seu alinhamento para a automaticidade do processo (Quadro 1). Traços graduais e descontínuos e hipercorreção atuam positivamente, porque demonstram acesso à rota lexical, possibilitando identificar maior automaticidade na leitura de palavras frequentes para o leitor. Já erros de decodificação e falta de conhecimento dos princípios do sistema alfabético do português atuam negativamente, por demonstrarem acesso à rota fonológica em um contexto não esperado, o que sinaliza a falta de automaticidade.

A compreensão leitora pode ser aferida indiretamente por meio das predições na leitura em voz alta, no sentido de prever e antecipar o que estar por vir no texto, as quais, no leitor proficiente, são, na maior parte dos casos, bemsucedidas, permitindo a confirmação das hipóteses e construção do significado do texto. Esse tipo de predição não é possível identificar no leitor hábil. Já o leitor fracassado não consegue prever e antecipar o que está por vir no texto pelas pistas linguísticas, possivelmente, porque está com todo o seu recurso cognitivo voltado para a decodificação da palavra escrita, o que também não permite identificar predições, porque neste caso sequer são construídas.

As predições que podem ser aferidas na leitura em voz alta são as que não foram exitosas, que podem ser de quatro tipos: i) mesma classe gramatical e mesmo campo semântico; ii) mesma classe gramatical e campo semântico diferente; iii) classe gramatical diferente e mesmo campo semântico; iv) e classe gramatical e campo semântico diferentes. Cada tipo de predição tem um peso no processo da compreensão na leitura. Como são processos em que o leitor não obteve sucesso, todos atuam negativamente, sendo as predições de maior peso aquelas sem relação com o mesmo campo semântico da palavra escrita.

Quadro 1 - Instrumento para Avaliação da Fluência em Leitura em voz alta: dimensão da precisão

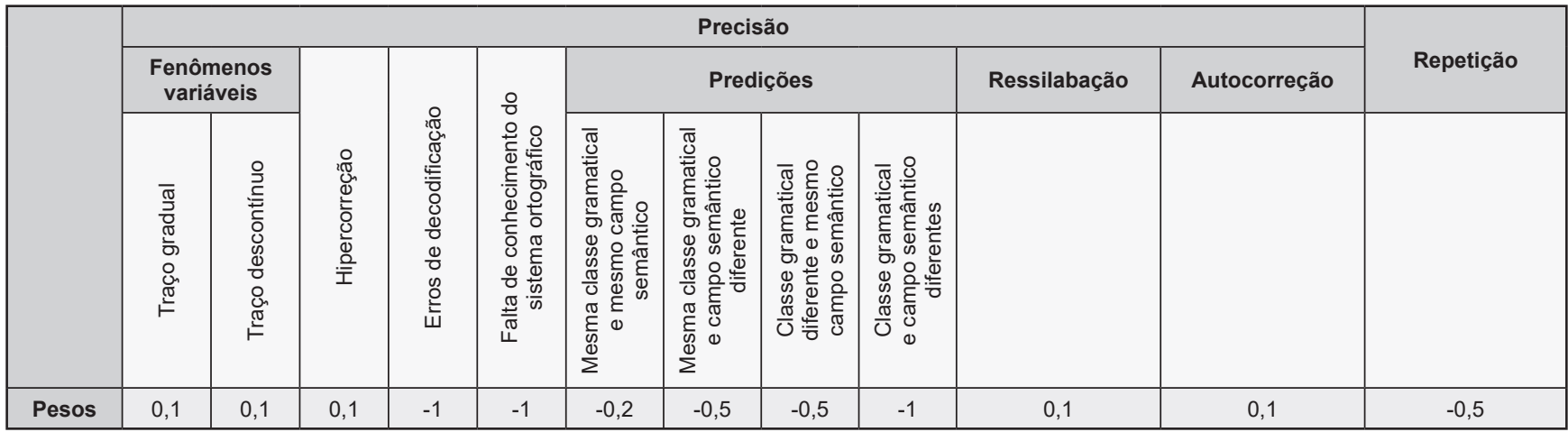

Fonte: Elaborado pelas autoras com dados da pesquisa. 
A ressilabação e as pausas silenciosas na leitura em voz alta possibilitam identificar a capacidade de organização do texto em bloco sintático-semânticos, o que também dá pistas da compreensão. Importam como pistas na leitura em voz alta as ressilabações que não foram realizadas e as pausas acima de $250 \mathrm{~ms}$ realizadas em outros contextos que não sejam fronteira de constituinte, como entre determinante e núcleo de sintagma. A mudança de fronteira refere-se ao contexto de desrespeito ao empacotamento sintático sinalizado no texto escrito, como a não obediência ao ponto final de uma frase, como sinal de conclusão da ideia apresentada, o que interfere no significado do texto (Quadro 2).

Quadro 2 - Avaliação da fluência em leitura em voz alta: dimensão da prosódia

\begin{tabular}{|l|l|l|l|}
\hline \multirow{2}{*}{ Estudante } & \multicolumn{3}{|l|}{ Análise da leitura prosódica } \\
\cline { 2 - 4 } & Pausa silenciosa & Pausa preenchida & Mudança de fronteira \\
\hline Pesos & $-0,5$ & $-0,5$ & -1 \\
\hline
\end{tabular}

Fonte: Elaborado pelas autoras com dados da pesquisa.

Autocorreções e repetições de palavras e de parte delas na leitura em voz alta configuram-se como pistas de processos de monitoramento da compreensão da leitura. As autocorreções atuam positivamente, por realizar reparos para a construção do significado do texto, enquanto as repetições atuam negativamente, por não contribuir para a compreensão do texto, embora atuem como processos de planejamento da leitura.

O cálculo da fluência em leitura em voz alta atende ao número de palavras lidas em 1 minuto somado aos processos realizados pelo leitor na leitura em voz alta, respeitados os pesos de cada um, dividido pelo número de palavras lidas (Quadro 3).
Quadro 3 - Cálculo da fluência em leitura em voz alta

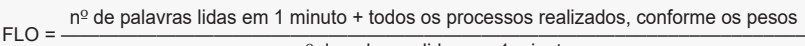
no de palavras lidas em 1 minuto

Fonte: Elaborado pelas autoras com dados da pesquisa

Esse parâmetro permitiu verificar a contribuição da velocidade para a automaticidade na leitura.

\section{Método de testagem do instrumento de diagnóstico}

Para testar o instrumento de diagnóstico, seguimos o método Curriculum-Based Measurement (DENO, 2003), para o controle destas pistas em um minuto de leitura em voz alta de dois textos extraídos dos livros didáticos da primeira e da última série do segundo ciclo do ensino fundamental ( $6^{\circ}$ e $9^{\circ}$ ano), e formatados para a realização da atividade de leitura em voz alta. ${ }^{2}$

Além da velocidade, medida pelo número de palavras ortográficas lidas durante um minuto, foram computadas a quantidade de realização dos processos de automaticidade, compreensão e monitoramento da compreensão leitora. $\mathrm{O}$ cômputo de cada processo recebeu um peso, em função de sua atuação de maior ou menor probabilidade de sinalizar a compreensão da leitura, a partir dos quais foram calculadas médias ponderadas, como explicitado nos Quadros 1-3.

A coleta (CAAE 2.008.797) foi realizada no início do ano letivo de 2016, em duas escolas públicas de Sergipe, Colégio Estadual Ministro Petrônio Portela (CEMPP) e Colégio de Aplicação da Universidade Federal de Sergipe (Codap/UFS), com 146 estudantes dos ciclos finais (6o e 9o anos) do ensino fundamental (Tabela 1).

Tabela 1 - Caracterização dos participantes da pesquisa

\begin{tabular}{|c|c|c|c|c|c|c|c|c|}
\hline \multirow{3}{*}{ Turma } & \multicolumn{4}{|c|}{ CEMPP } & \multicolumn{4}{|c|}{ Codap/UFS } \\
\hline & \multirow{2}{*}{ Participantes } & \multicolumn{2}{|c|}{ Sexo } & \multirow{2}{*}{ Idade } & \multirow{2}{*}{ Participantes } & \multicolumn{2}{|c|}{ Sexo } & \multirow{2}{*}{ Idade } \\
\hline & & Feminino & Masculino & & & Feminino & Masculino & \\
\hline 6o ano A & 18 & 10 & 8 & 10 a 13 & 23 & 13 & 10 & 10 a 13 \\
\hline 60 ano B & 13 & 5 & 8 & 10 a 14 & 20 & 10 & 10 & 10 a 12 \\
\hline 9o ano $A$ & 9 & 4 & 5 & 13 a 15 & 23 & 7 & 16 & 13 a 17 \\
\hline 9o ano B & 7 & 6 & 1 & 13 a 17 & 12 & 6 & 6 & 13 a 15 \\
\hline 9o ano C & 12 & 10 & 2 & 14 a 16 & - & - & - & - \\
\hline 9o ano D & 9 & 3 & 6 & 14 a 19 & - & - & - & - \\
\hline Total & 68 & 38 & 30 & & 78 & 36 & 42 & \\
\hline
\end{tabular}

Fonte: Elaborado pelas autoras com dados da pesquisa

\footnotetext{
2 Os textos utilizados para a leitura em voz alta dos informantes desta pesquisa para avaliação da fluência em leitura em voz alta atendem ao nível de escolaridade do estudante participante, pois foram selecionados a partir de livros didáticos dos $6^{\mathrm{O}}$ e 9 을 anos do Programa Nacional do Livro Didático (PNLD) de 2011. BORGATTO, Ana Maria Trinconi; BERTIN, Terezinha Costa Hashimoto; MARCHESI, Vera Lúcia de Carvalho. Tudo é linguagem. 60 Ano. São Paulo: Ática, 2009.

SOARES, Magda. Português: uma proposta para o letramento. 9o Ano. 1. ed. São Paulo: Moderna, 2009. CEREJA, William Roberto; MAGALHÃES, Thereza Cochar. Português: Linguagens, 6oano/9oano. 5. ed. São Paulo: Atual, 2009.

A seleção dos textos obedece aos critérios de: 1) ser um texto compatível com o nível de escolaridade dos leitores (CBM); 2) haver elementos linguísticos passíveis de uso variável na oralidade; 3) haver elementos linguísticos do cotidiano dos estudantes leitores, como também elementos novos;
} 
A sessão de gravação da leitura em voz alta de dois textos foi realizada de forma individual, em ambiente reservado, previamente agendado com a coordenação das escolas. Cada estudante leu em voz alta dois textos, que foram gravados em áudio e em vídeo, e posteriormente transcritos no software Elan (WITTENBURG et al., 2006).

\section{Resultados e discussão}

Após a análise da leitura em voz alta de dois textos por estudantes do 6o e $9^{\circ}$ ano do ensino fundamental de duas escolas públicas de Sergipe, descrevemos o comportamento dos leitores quanto aos processos de automaticidade, compreensão e monitoramento. A dimensão da velocidade na fluência em leitura em voz alta é um parâmetro que permite verificar o número de palavras que o leitor lê em relação ao tempo gasto na leitura em voz alta.

Gráfico 1 - Velocidade de leitura por série

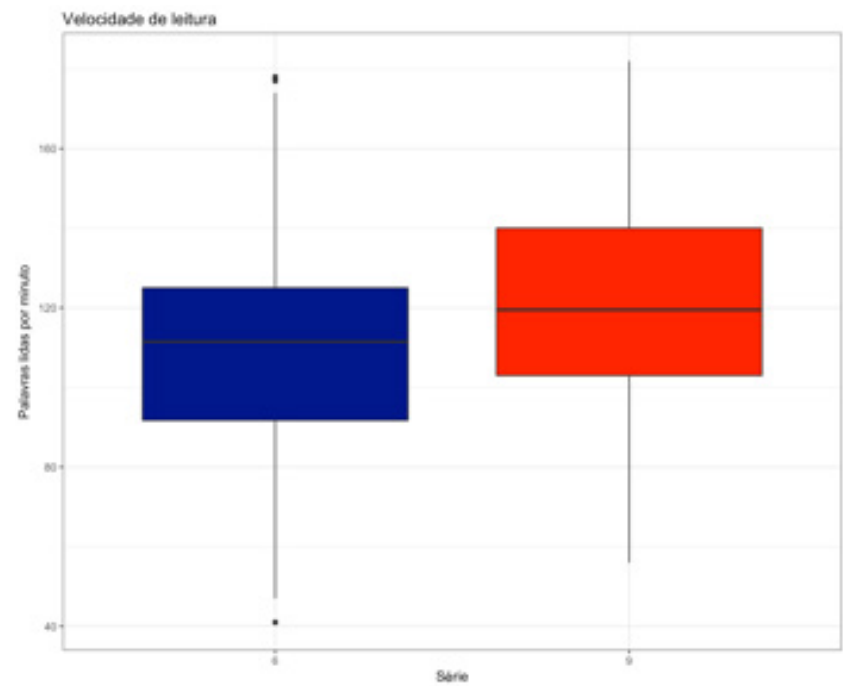

Fonte: Elaborado pelas autoras com dados da pesquisa.

A distribuição dos dados de velocidade em função das séries é normal $\left(\mathrm{M}=0,99, \mathrm{p}=0,37\right.$ para o $6^{0}$ ano e $\mathrm{M}=0,99, \mathrm{p}=0,62$ para o 9 o ano) e as variâncias são homogêneas $(\mathrm{F}=0,45 \mathrm{p}=0,49)$. A distribuição dos resultados considera a média para a automaticidade em

4) ser um texto relativamente curto, mas, ao mesmo tempo, com tamanho suficiente para garantir a espontaneidade da leitura; 5) ter palavras comuns e não muito longas; 6) estar na ordem direta das sentenças; 8) não apresentarem passagens com diálogos; 9) ser um texto com temática adequada; e 10) não ter nomes próprios, siglas, palavras estrangeiras e números grandes. Os textos selecionados foram formatados em fonte Times New Roman, tamanho 14 espaçamento 1,5 , com o trecho do texto delimitado por uma margem. A formatação do texto é importante para que as ocorrências de translineação e a diagramação não interfiram no processo de leitura. intersecção com a média de palavras lidas por minutos. A progressão escolar contribui para o incremento na velocidade de leitura: estudantes do $9^{\circ}$ ano leem mais palavras por minuto $(M=120,4, \mathrm{SD}=25,8)$ do que estudantes do $6^{\circ}$ ano $(M=108,5, \mathrm{SD}=28,7)$, e essa diferença é significativa $(\mathrm{t}=-3,77, \mathrm{df}=290, \mathrm{p}=0,0001)$.

Gráfico 2 - Desempenho dos estudantes quanto às pistas de automaticidade na leitura em voz alta

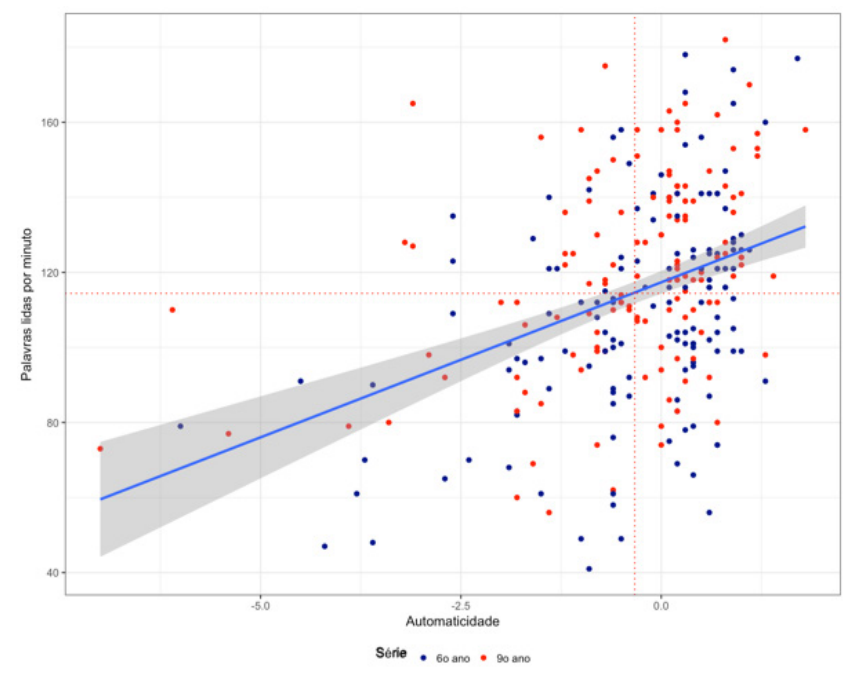

Fonte: Elaborado pelas autoras com dados da pesquisa.

Notas: A linha azul contínua representa o coeficiente estimado para o escore da média ponderada dos parâmetros de automaticidade em um modelo de regressão linear. As linhas vermelhas pontilhadas representam as médias das palavras lidas por minuto (horizontal) e de automaticidade (vertical).

O controle das pistas de automaticidade (Gráfico 2) sugere que, quanto mais palavras lidas por minuto, mais automatizado é o leitor $\left[\beta=-2,45( \pm 0,30), \mathrm{t}=-8,116^{* * *}\right]$.

Gráfico 3 - Desempenho dos estudantes quanto às pistas de compreensão na leitura em voz alta

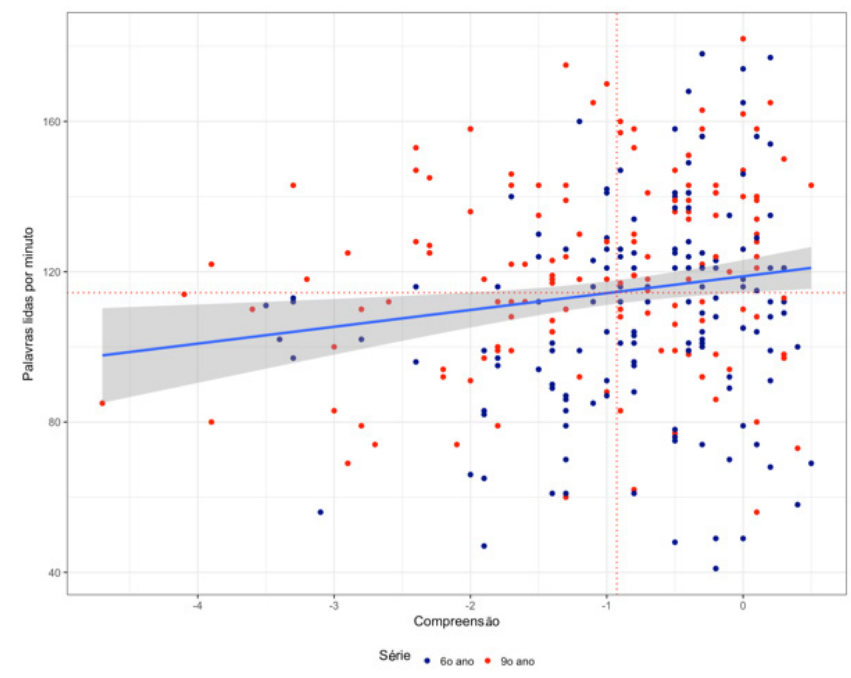

Fonte: Elaborado pelas autoras com dados da pesquisa.

Notas: A linha azul contínua representa o coeficiente estimado para o escore da média ponderada dos parâmetros de compreensão em um modelo de regressão linear. As linhas vermelhas pontilhadas representam as médias das palavras lidas por minuto (horizontal) e de compreensão (vertical). 
No entanto, a leitura automatizada não necessariamente implica em compreensão leitora. Os resultados do controle das pistas de compreensão (Gráfico 3) em função do número de palavras lidas por minuto apontam, também, para uma correlação positiva $[\beta=-1,56( \pm 0,24)$, $\mathrm{t}=-6,482 * * *]$.

Gráfico 4 - Desempenho dos estudantes quanto às pistas de monitoramento da compreensão na leitura em voz alta

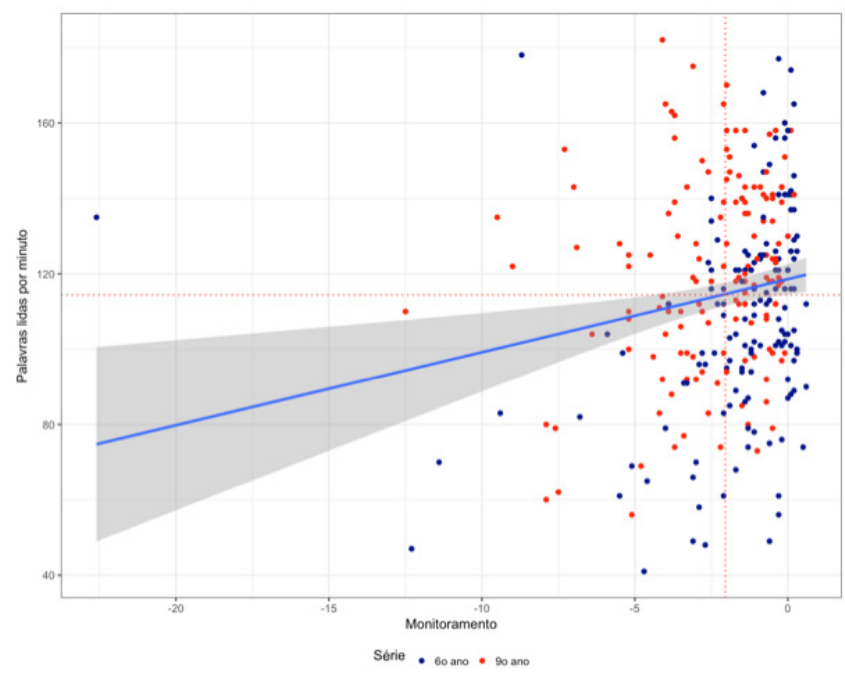

Fonte: Elaborado pelas autoras com dados da pesquisa.

Notas: A linha azul contínua representa o coeficiente estimado para o escore da média ponderada dos parâmetros de monitoramento da compreensão em um modelo de regressão linear. As linhas vermelhas pontilhadas representam as médias das palavras lidas por minuto (horizontal) e de monitoramento da compreensão (vertical).

Gráfico 5 - Desempenho dos estudantes quanto à fluência em leitura em voz alta considerando as pistas de automaticidade, compreensão e monitoramento da compreensão controladas

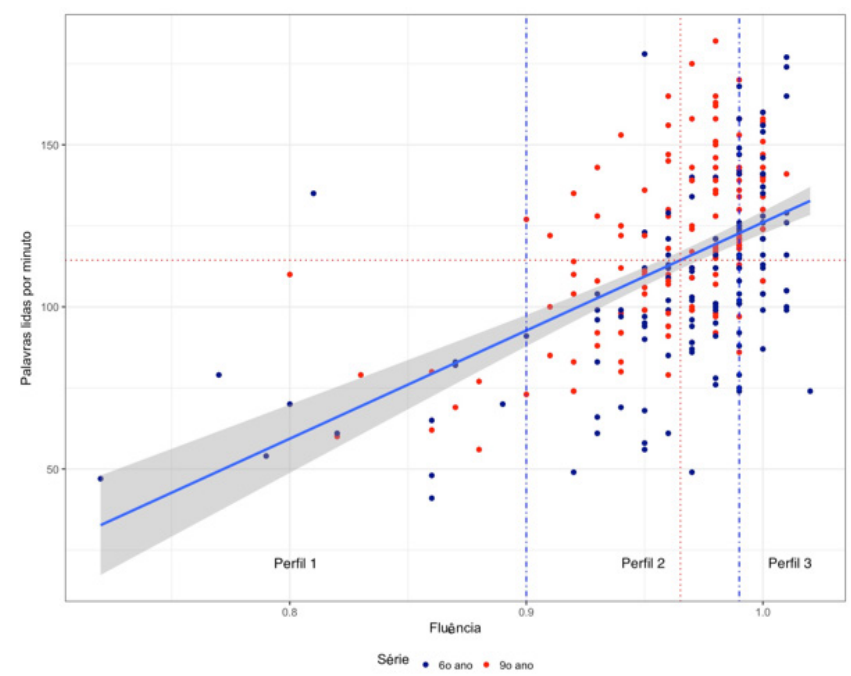

Fonte: Elaborado pelas autoras com dados da pesquisa.

Notas: A linha azul contínua representa o coeficiente estimado para a média ponderada de fluência considerando os parâmetros de automaticidade compreensão e monitoramento da compreensão em um modelo de regressão linear. As linhas vermelhas pontilhadas representam as médias das palavras lidas por minuto (horizontal) e da fluência (vertical). As linhas azuis pontilhadas sinalizam os perfis de leitor (MORAIS, 1996).
Na mesma direção seguem os resultados do controle das pistas de monitoramento (Gráfico 4) em função do número de palavras lidas por minuto: quanto mais palavras lidas por minuto, maior a ocorrência de pistas de monitoramento $\left[\beta=-3,89( \pm 0,62), \mathrm{t}=-6,253^{* * *}\right]$.

O cálculo da fluência em leitura em voz alta considera a velocidade de leitura de palavras por minuto somada aos escores dos processos realizados pelo leitor na leitura em voz alta, respeitados os pesos de cada um, dividido pelo número de palavras lidas em um minuto, o que gera um escore individual (Gráfico 5), que também segue a direção do controle de cada um dos escores dos processos $[\beta=0,0868( \pm 0,00093), \mathrm{t}=-93,19 * * *]$.

A distribuição dos escores de fluência em leitura em voz alta pode ser dividida em três perfis de leitor, que apresentam semelhança com a descrição proposta por Morais (1996), na introdução deste texto.

\subsection{Perfil 1}

Com escore entre 0,72 a 0,90 ; o padrão de leitura deste perfil (13) demonstra falta de automaticidade, muitos processos de compreensão malsucedidos e falta de monitoramento da compreensão da leitura. A velocidade de leitura é mais lenta e a tarefa se mostra laboriosa. Este tipo de leitor está com a atenção voltada para a decodificação da palavra e os recursos cognitivos não são acessados para a compreensão do texto lido, assim os processos de predição de leitura para a compreensão do texto não são exitosos e os processos metacognitivos de monitoramento da compreensão não avaliam essas predições nem realizam reparos adequados ao texto escrito.

(13) todos os dias a meninas estava lá $(0,350)$ vendia... $(0,430)$ do- $\ldots(0,220)$ do- $\ldots(0,284)$ doce $\ldots(0,385)$ na porta de uma... $(0,444)$ la-chonete... $(0,866)$ preto... $(0,276)$ de uma gracinha $(0,289)$ onde... $(0,345)$ brincava... $(0,411)\{$ craci\} ... $(0,311)$ bran-... $(0,775) /$ $\{$ graci\} ... $(0,336)$ todas a... $(0,160)$ \{griações\}... $(0,377)$ da reton-... $(0,548)$ re-ton-testa... $(0,856)$ reton-testa $(2,620)$ re- $\ldots(0,235)$ ton-... $(0,761)$ re-... $(0,213)$ to-... $(1,689)$ \{retontessa\} mas ela... $(0,376)$ não brincava $(0,230) \mathrm{s}-\ldots(0,428)$ só vendia... $(0,341)$ doces mesmo... $(0,440)$ porque ela... $(0,160)$ não era... $(0,252)$ mora- $\ldots(0,329)$ moradora... $(0,377)$ do... $(0,527)$ \{baíro $\ldots . .(0,503)$ paí-... $(0,476)$ \{par-... íro $\ldots(0,570)$ /bárrio $(0,357)$ sempre chegava por... $(0,403)$ volta das... $(0,454)$ g- $\ldots(0,238)$ \{grando $\}]$ DFG-6MEFE-05.16-V1-T1

Se fossem estudantes do primeiro ciclo do ensino fundamental, este perfil seria de um leitor iniciante. Mas, 
considerando que os estudantes da amostra são dos anos finais do ensino fundamental, este perfil corresponde a um leitor fracassado, que não desenvolveu as condições necessárias à aprendizagem inicial da leitura.

\subsection{Perfil 2}

Com escore entre 0,91 a 0,99; o padrão de leitura deste perfil (14) demonstra que os processos de leitura melhoraram, em relação ao perfil 1 , mas ainda há falta de automaticidade na decodificação; são leitores que realizam mais reparos nas predições malsucedidas, porque há realização de processos de monitoramento da compreensão da leitura.

(14) a primeira presença em um... em /meu... aprendiaprendizado... escolar que meu... calçou o sapato in... calça... calça até hoje foi uma jovem professorinha em cla-... clara... /claro que eu s-... eu... uso esse tem- tempo... professorinha com muitos... /muito... alfe-... \{alfeito $\}$ chamava-se Eu-... Eunice... Vacon-... ce- Vasconcelo e foi com ela que eu aprendi a fazer o que ela chamava de... sen-... certeza... /certezas eu já sabia... e... lê escrever] CRMS-6MEFF-08.16-V1-T2

Este perfil também é o leitor fracassado, mas em um nível mais acima do que o anterior, que ainda está no processo de desenvolvimento automatizado de rotas lexicais. No entanto, leitores deste perfil ainda estão com a atenção voltada para a decodificação, realizam menos predições improdutivas e fazem mais reparos das predições para tentar construir o significado do texto. A velocidade de leitura apresenta grande variabilidade. A leitura mais lenta contribuiu para menos erros de decodificação, mais predições adequadas ao texto escrito e realização de reparos durante a leitura. Assim, a leitura mais lenta contribuiu para que o leitor usasse de forma mais adequada os processos de decodificação, compreensão e monitoramento da compreensão. Já na leitura mais rápida, o leitor cometeu mais erros de decodificação e fez mais predições malsucedidas com menos reparos na leitura em voz alta.

Os perfis 1 e 2 de leitor assemelham-se ao que Morais (1996) define como leitor fracassado, uma vez ainda não terem desenvolvido as condições da aprendizagem inicial da leitura (FRITH, 1985; EHRI, 2013; MORAIS; LEITE; KOLINSKY, 2013), o que é esperado por seu nível de escolarização (anos finais do ensino fundamental).

\subsection{Perfil 3}

Com escores entre 1,0 e 1,02, o padrão de leitura deste perfil (15) demonstra que os leitores desenvolveram a automaticidade na decodificação e o monitoramento da compreensão da leitura e realizam menos predições malsucedidas. Os leitores desse perfil direcionam a atenção para a compreensão e o monitoramento da compreensão da leitura, realizando os processos de predição de leitura para a compreensão do texto de forma exitosa e os processos metacognitivos de monitoramento da compreensão avaliam essas predições com reparos adequados ao texto escrito.

(15) todos os dias a menininha estava lá... vendia doces na porta de uma lanchonete... perto de uma pracinha... onde brincam quase todas as crianças... da redondeza... mas ela não brincava... só vendia doces... mesmo porque ela não era moradora do bairro... sempre chegava por volta das... quatro da tarde e ficava até os doces... acabarem... nos finais da se- /de semana ela chegava mais tarde... mas nunca faltava... devia ter uns $\{$ oitos $\}$ an- anos e... às vezes distraía-se... olhando as crianças brincarem... quando eu era menina... queria ter uma fábrica de doces só para poder comer todos os doces ... que eu quisesse... naquela época eu era muito pobre... e quase nunca sobrava dinheiro lá em casa para comprar doces... a menininha não comia nenhum... ficava lá até vender todos] SJSS-6MEFF-08.16-V1-T1.

Este é o padrão de comportamento de um leitor hábil, que desenvolveu todas as condições dos processos do modelo de leitura para ler com automaticidade, demonstrando eficiência e fluência na leitura em voz alta. Este seria o padrão esperado para todos os estudantes ao final do terceiro ano do ensino fundamental, momento em que o processo de aprendizagem inicial da leitura deveria estar concluído, como evidencia a Avaliação Nacional da Alfabetização (ANA).

A concentração de leitores fracassados - por estarem nos anos finais do ensino fundamental sem terem consolidado a aprendizagem inicial da leitura pode ser uma pista para entender os resultados obtidos nas avaliações oficiais em larga escala que aferem leitura.

\section{Fluência em leitura em voz alta e compreensão}

A fluência em leitura em voz alta pode repercutir nos resultados de avaliações em larga escala que avaliam a proficiência na compreensão em leitura. Portugal alavancou seus resultados no PISA depois da adoção de estratégias pedagógicas para a fluência em leitura, incluindo a avaliação da fluência em leitura em voz alta. Nos Estados Unidos, a prática de diagnóstico da leitura a partir da avaliação da automaticidade na decodificação 
em voz alta faz parte do cotidiano escolar, como um processo de identificar o leitor fluente. Desde 2000, os educadores passaram a aferir o nível de fluência em leitura em voz alta de estudantes do $1^{\mathrm{O}}$ ao $9^{\underline{0}}$ ano da educação básica e direcionam a instrução adequada para dirimir a dificuldade em leitura identificada (DENO, 2001, 2003; RASINSKI, 2000, 2004; RASINSKI et al., 2005, 2011; HASBROUCK; TINDAL, 2006). Em Portugal, as pesquisas sobre leitura na perspectiva da automaticidade na decodificação se fortaleceram a partir de 2006, quando o Ministério da Educação lançou o Programa Nacional de Leitura (PNL), com o objetivo de promover avaliações de leitura para assegurar aos estudantes a aquisição das competências básicas de leitura (automaticidade na decodificação) nas primeiras etapas da vida escolar, de forma a evitar dificuldades que progressivamente se acumulem, se multipliquem e se transformem em obstáculos quase intransponíveis (SIM-SIM; VIANA, 2007). A partir da experiência norte-americana, pesquisadores portugueses têm desenvolvido propostas de diagnóstico das competências básicas de leitura que levam à compreensão do texto lido (TRISTÃO, 2009; COELHO, 2010; CASTANHEIRA, 2011; COLLUS; 2015).

O Pisa, realizado pela Organização para a Cooperação e Desenvolvimento Econômico (OCDE), avalia o nível de habilidade em matemática, leitura e ciências de estudantes de diferentes países. A avaliação ocorre a cada três anos para estudantes na faixa etária dos 15 anos, idade que corresponde à conclusão do ensino fundamental no Brasil, e avalia, por amostragem, estudantes de escolas públicas e particulares. A avaliação verifica até que ponto as escolas de cada país participante estão preparando os jovens para exercer o papel de cidadãos na sociedade contemporânea (BRASIL, 2016).

Apesar de não ser um país-membro da OCDE, o Brasil participa do Pisa desde 2000. Considerando a perspectiva de diagnóstico do nível de leitura nos Estados Unidos e em Portugal, percebemos que os resultados nas avaliações do Pisa têm apresentado uma progressão no desenvolvimento da leitura, como podemos observar nos resultados de proficiência em leitura nas edições de 2000 a 2015 do PISA (Tabela 2).

Tabela 2 - Proficiência em leitura no Pisa - 2000 a 2015

\begin{tabular}{lcccccc}
\hline & $\mathbf{2 0 0 0}$ & $\mathbf{2 0 0 3}$ & $\mathbf{2 0 0 6}$ & $\mathbf{2 0 0 9}$ & $\mathbf{2 0 1 2}$ & $\mathbf{2 0 1 5}$ \\
Estados Unidos & 504 & 495 & - & 500 & 498 & 497 \\
Portugal & 470 & 478 & 472 & 489 & 488 & 498 \\
Brasil & 396 & 403 & 393 & 412 & 410 & 407 \\
\hline
\end{tabular}

Fonte: Elaborado pelas autoras com dados do relatório do Pisa (BRASIL, 2016).

Há um crescente progresso em leitura nos resultados do Pisa de Portugal, que apresentava média de 470 pontos em 2000 e obteve 498 em 2015. Portugal e Estados Unidos alcançaram a proficiência de nível 3, que concentra a maioria dos resultados dos países da OCDE.

Já a média dos estudantes brasileiros na avaliação de leitura no Pisa, em 2015, atingiu 407 pontos, valor significativamente inferior à média de Portugal e Estados Unidos, e que coloca os estudantes brasileiros abaixo do nível 2 em leitura, patamar que a OCDE estabelece como necessário para que o estudante possa exercer plenamente sua cidadania.

A fluência em leitura em voz alta pode repercutir nos resultados de avaliações em larga escala que avaliam a proficiência na compreensão em leitura. As experiências internacionais sugerem que o diagnóstico dos processos de decodificação com automaticidade propicia o desenvolvimento dos processos de compreensão, e esta é uma solução que pode ser adotada no sistema educacional brasileiro.

\section{Considerações finais}

O detalhamento de um instrumento de diagnóstico de perfil de leitores pode contribuir para a abordagem pedagógica da leitura, ao permitir que seja avaliado o desempenho do estudante nos processos de decodificação e de compreensão a partir de pistas identificadas na leitura em voz alta. Com o treinamento do professor, a partir da leitura em voz alta na situação de sala de aula, é possível identificar os perfis de leitor, assim como qual a sua dificuldade específica, com o aprimoramento e adaptação da proposta do método Curriculum-Based Measurement para o português brasileiro para avaliar a fluência em leitura (ALMEIDA; FREITAG, 2012; OLIVEIRA; AMARAL; PICANÇO, 2013; PICANÇO; VANSILER, 2014; MOUTINHO, 2015; VANSILER, 2015; OLIVEIRA, 2015; MACHADO, 2018b).

\section{Referências}

ABREU, Kátia Nazareth Moura et al. O teste de Cloze como instrumento de medida da proficiência em leitura: fatores linguísticos e não linguísticos. Revista de Estudos da Linguagem, Belo Horizonte, v. 25, n. 3, p. 1767-1799, 2017. https://doi.org/10.17851/2237-2083.25.3.1767-1799

ALMEIDA, Ayane Nararela Santos; FREITAG, Raquel Meister Ko. Análise do diagnóstico do desempenho em leitura: Provinha Brasil vs. fluência em leitura oral. Signo, Santa Cruz do Sul, v. 37, n. 63, p. 98-110, 2012.

ALMEIDA, Vanessa Borges. Pausas preenchidas e domínios prosódicos: evidências para a validação do descritor fluência em um teste de proficiência oral em língua estrangeira. ALFA: Revista de Linguística, São Paulo, v. 53, n. 1, p. 167-193, 2009. 
ALVES, Luciana Mendonça; REIS, César Augusto da Conceição; PINHEIRO, Ângela Maria Vieira; CAPELLINI, Simone Aparecida. Aspectos prosódicos temporais da leitura de escolares com dislexia do desenvolvimento. Revista da Sociedade Brasileira de Fonoaudiologia, São Paulo, v. 14, n. 2, p. 197-204, 2009. https://doi.org/10.1590/S151680342009000200010

AQUINO, Maria de Fátima de Souza. Uma proposta de tipologia de erros de leitura: análise sociolinguística e cognitiva. 2011, 156 p. Tese (Doutorado em Linguística) Universidade Federal da Paraíba, João Pessoa. 2011.

BISOL, Leda. Os constituintes prosódicos. In: BISOL, Leda (org.). Introdução a estudos de fonologia do português brasileiro. Porto Alegre: EdiPUCRS, p. 243-255, 1996.

BORTONI-RICARDO, Stella Maris. Educação em língua materna: a sociolinguística na sala de aula. São Paulo: Parábola, 2004.

BRASIL. Ministério da Educação. Instituto Nacional de Estudos e Pesquisas Educacionais Anísio Teixeira. Brasil no PISA 2015: análises e reflexões sobre o desempenho dos estudantes brasileiros. São Paulo: Fundação Santillana, 2016.

BRASIL. Ministério da Educação. Secretaria de Educação Média e Tecnológica. Parâmetros Curriculares Nacionais. Ensino Fundamental: Terceiro e Quartos Ciclos: Língua Portuguesa. Brasília: SEF, 1998.

CASTANHEIRA, António José Alexandre. Avaliação da fluência da leitura oral em alunos do 50 ano de escolaridade. 2011, 49 p. Dissertação (Mestrado em Psicologia).

Universidade de Lisboa, Lisboa, 2011.

COELHO, Joana Rita Quaresma. Estimulação da fluência oral: proposta de actividades e estudo exploratório. 2010, 54 p. Dissertação (Mestrado em Psicologia). Universidade de Lisboa, Lisboa, 2010.

COLLUS, Jorge André Rocha Alves Soveral. Impacto da fluência de leitura e da metacompreensão na compreensão da leitura. 2015, 28 p. Dissertação (Mestrado Integrado em Psicologia) - Universidade do Minho, Braga, 2015.

COLTHEART, Max; RASTLE, Kathleen; PERRY; Conrad; LANGDON, Robyn; ZIEGLER, Johannes. DRC: a dual route cascaded model of visual word recognition and reading aloud. Psychological review, v. 108, n. 1, p. 204, 2001. https://doi. org/10.1037//0033-295X.108.1.204

COLTHEART, Max. Modelando a leitura: a abordagem da dupla rota. In: SNOWLING, Margaret J.; HULME, Charles (org.). A Ciência da Leitura. Porto Alegre: Penso, 2013. p. 24-41.

DEHAENE, Stanislas. Os neurônios da leitura. Porto Alegre: Penso, 2012.

DENO, Stanley L. Developments in curriculum-based measurement. The Journal of Special Education, New York, n. 37, v. 3. p. 184-192, 2003. https://doi.org/10.1177/0022466 9030370030801
EFKLIDES, Anastasia. Metacognition: Defining its facets and levels of functioning in relation to self-regulation and co-regulation. European Psychologist, London, v. 13, n. 4, p. 277-287, 2008. https://doi.org/10.1027/1016-9040.13.4.277

EHRI, Linnea C. O desenvolvimento da leitura imediata de palavras: fases e estudos. In: SNOWLING, Margaret J.; HULME, Charles (org.). A ciência da leitura. Porto Alegre: Penso Editora, 2013. p. 153-172.

FREITAG, Raquel Meister Ko; PINHEIRO, Bruno Felipe Marques; SILVA, Lucas Santos. Análise variacionista de pausas preenchidas em fronteiras de constituintes. In: FREITAG, Raquel Meister Ko, LUCENTE, Luciana (org.). Prosódia da fala. São Paulo: Blucher, 2017, p. 117-132. https://doi.org/10.5151/9788580392593-07

FREITAG, Raquel Meister Ko; SÁ, José Júnior de Santana. Leitura em voz alta: variação linguística e o sucesso na aprendizagem inicial da leitura. No prelo (2019).

FRITH, Uta. Beneath the surface of developmental dyslexia. Surface dyslexia, [s. l.], v. 32, n.1, p. 301-330, 1985. https:// doi.org/10.4324/9781315108346-18

FUCHS, Lynn S.; FUCHS, Douglas; HOSP, Michelle K. Oral reading fluency as an indicator of reading competence: A theoretical, empirical, and historical analysis. Scientific studies of reading, London, v. 5, p.3, p. 239-256, 2001. https://doi.org/10.1207/S1532799XSSR0503_3

GOODMAN, Kenneth S. Reading: a psycholinguistic guessing game. Journal of the Reading Specialist, London, v. 6 , n. 4, p. 126-135, 1967. https://doi.org/10.1080/ 19388076709556976

HASBROUCK, Jan; TINDAL, Gerald A. Oral reading fluency norms: A valuable assessment tool for reading teachers. The Reading Teacher, Newark, Del., US: v. 59, n. 7, p. 636-644, 2006. https://doi.org/10.1598/RT.59.7.3

KOMENO, Eliana Matiko; ÁVILA, Clara Regina Brandão de; CINTRA, Isa de Pádua; SCHOEN, Teresa Helena. Velocidade de leitura e desempenho escolar na última série do ensino fundamental. Estudos de Psicologia, Campinas, v. 32, n. 3, p. 437-447, 2015. https://doi.org/10.1590/0103166X2015000300009

LABERGE, David; SAMUELS, S. Jay. Toward a theory of automatic information processing in reading. Cognitive psychology, New York, v. 6, n. 2, p. 293-323, 1974. https://doi.org/10.1016/0010-0285(74)90015-2

LABOV, William. Sociolinguistics patterns. Pennsylvania: University of Pennsylvania Press, 1972.

LOGAN, Gordon D. Automaticity and reading: Perspectives from the instance theory of automatization. Reading \& Writing Quarterly: Overcoming Learning Difficulties, London, v. 13, n. 2, p. 123-146, 1997. https://doi.org/10.1080/ 1057356970130203

MACHADO, Alessandra Pereira Gomes. Variação linguística e leitura: fenômenos variáveis da fala na leitura em voz alta. $A$ 
Cor das Letras, Feira de Santana, BA, v. 19, n. 4, p. 196-218, 2018a. https://doi.org/10.13102/cl.v19i4Especial.2867

MACHADO, Alessandra Pereira Gomes. Fluência em leitura oral e compreensão em leitura: automaticidade na decodificação para a compreensão leitora. 2018, 209 f. Tese (Doutorado em Educação) - Universidade Federal de Sergipe, São Cristóvão. 2018b.

MORAIS, José; LEITE, Isabel; KOLINSKY, Régine. Entre a pré-leitura e a leitura hábil: Condições e patamares da aprendizagem. In: MALUF, Maria Regina; CARDOSOMARTINS, Cláudia (org.). Alfabetização no século XXI: Como se aprende a ler e a escrever. São Paulo: Penso, 2013, p. 17-48.

MORAIS, José. A arte de ler. São Paulo: EdUNESP, 1996. MOUTINHO, Michaell Gadelha. A Precisão na Fluência em Leitura Oral: avaliando a leitura de alunos do 60 ano do ensino fundamental. 2015, 112 p. Dissertação (Mestrado em Letras) - Universidade Federal do Pará, Belém. 2015.

OAKHILL, Jane; HARTT, Joanne; SAMOLS, Deborah. Levels of comprehension monitoring and working memory in good and poor comprehenders. Reading and writing, Dordrecht, NL: v. 18, n. 7-9, p. 657-686, 2005. https://doi. org/10.1007/s11145-005-3355-Z

OLIVEIRA, Elisangela R.; AMARAL, Shirlene Betrice G.; PICANÇO, Gessiane. Velocidade e precisão na leitura oral: identificando alunos fluentes. Nonada: Letras em Revista, Porto Alegre, v. 2, n. 21, p. 1-13, 2013.

OLIVEIRA, Elisangela Ribeiro de. A Estratégia da Velocidade na Fluência em Leitura Oral: um diagnóstico em seis escolas da região metropolitana de Belém. 2015, 90 p. Dissertação (Mestrado em Letras) - Universidade Federal do Pará, Belém 2015.

OLIVEIRA, Miguel. Pausing strategies as means of information processing in spontaneous narratives. In: SPEECH PROSODY 2002: INTERNATIONAL CONFERENCE. 2002. [Proceedings] [...]. [S. l.: s. n., [2002?].

PERFETTI, Charles; LANDI, Nicole; OAKHILL, Jane. A aquisição da habilidade de compreensão da leitura. In: SNOWLING, Margaret J.; HULME, Charles (Org.). A Ciência da Leitura. Porto Alegre: Penso, 2013, p. 245-265 https://doi.org/10.1080/10888438.2013.827687

PERFETTI, Charles; STAFURA, Joseph. Word knowledge in a theory of reading comprehension. Scientific Studies of Reading, London, v. 18, n. 1, p. 22-37, 2014.

PICANÇO, Gessiane Lobato; VANSILER, Nair. A prosódia e a leitura fluente. Gragoatá, Niterói, v. 19, n. 36, p. 157-174, 2014.

PINHEIRO, Bruno Felipe Marques, et al. Processos fonológicos que passam da fala para a leitura. In: AZEVEDO, Isabel Cristina Michelan; ROIPHE, Alberto (org.). Leitura, escrita e literatura: interseções e convergências. São Cristóvão: EdUFS, 2017. p. 10-25.

RASINSKI, Timothy V. Commentary: Speed does matter in reading. The Reading Teacher, Newark, Del., US, v. 54, n. 2 , p. 146-151, 2000. https://doi.org/10.1598/JAAL.49.1.3
RASINSKI, Timothy. Creating fluent readers. Educational Leadership, Washington, US, v. 61, n. 6, p.46-51, 2004.

RASINSKI, Timothy V. et al. Is reading fluency a key for successful high school reading? Journal of Adolescent \& Adult Literacy, Newark, Del., US, v. 49, n. 1, p. 22-27, 2005.

RASINSKI, Timothy V. et al. The relationship between a silent reading fluency instructional protocol on students' reading comprehension and achievement in an urban school setting. Reading Psychology, Newark, Del., US, v. 32, n.1, p. 75-97, 2011. https://doi.org/10.1080/02702710903346873

SCARPA, Ester Mirian; FERNANDEZ-SVARTSMAN, Flaviane. A estrutura prosódica das disfluências em português brasileiro. Cadernos de Estudos Linguísticos, Campinas, v. 54, n. 1, p. 25-40, 2012. https://doi.org/10.20396/cel. v54i1.8636969

SCLIAR-CABRAL, Leonor. Princípios do sistema alfabético do português do Brasil. São Paulo: Contexto, 2003.

SIM-SIM, Inês; VIANA, Fernanda Leopoldina. Para a avaliação do desempenho de leitura. Lisboa: Gabinete de Estatística e Planeamento da Educação, 2007.

SMITH, Frank. Understanding reading: A psycholinguistic analysis of reading and learning to read. New York: Routledge, 2004.

TRISTÃO, Flora Saudan Correia. Avaliação da fluência de leitura oral em alunos de 2a ano do $1^{\circ}$ ciclo. 2009, 46 p. Dissertação (Mestrado Integrado em Psicologia) Universidade de Lisboa, Lisboa. 2009.

VANSILER, Nair Daiane de Souza Sauaia. Expressividade oral e fluência em leitura: monitoramento e diagnóstico de cinco escolas estaduais de Belém do Pará. Dissertação (Mestrado em Letras) - Universidade Federal do Pará, Belém. 2015.

WITTENBURG, P. et al. Elan: a professional framework for multimodality research. In: LREC. Proceedings [...]. [S. l: s. n.], 2006.

Recebido em: 15/11/2018

Aprovado em: 25/5/2019.

Publicado em: 5/11/2019

\section{Autoras:}

Alessandra Pereira Gomes Machado

Doutora em Educação pela Universidade Federal de Sergipe (UFS). Professora na Universidade Federal de Sergipe, São Cristóvão, SE, Brasil. Orcid: http://orcid.org/0000-0003-2351-6299

E-mail: alessandrasjp@hotmail.com

Raquel Meister Ko. Freitag

Doutora em Linguística pela Universidade Federal de Santa Catarina (UFSC). Professora na Universidade Federal de Sergipe, São Cristóvão, SE, Brasil.

Orcid: http://orcid.org/0000-0002-4972-4320

E-mail: rkofreitag@uol.com.br

Endereço: Av. Marechal Rondon, s/n - Jardim Rosa Elze 49100-000, São Cristóvão, SE, Brasil 